\title{
MÉTODO ALTERNATIVO PARA ESTUDAR A FAUNA DO SOLO
}

\author{
ALTERNATIVE METHOD TO STUDY SOIL EDAPHIC FAUNA
}

Zaida Inês Antoniolli ${ }^{1}$ Paulo Cesar Conceição ${ }^{2}$ Valídio Böck ${ }^{2}$ Odair Port ${ }^{2}$ Danni Maisa da Silva ${ }^{2}$ Rodrigo Ferreira da Silva ${ }^{3}$

\section{RESUMO}

Os levantamentos realizados sobre populações da fauna edáfica podem não mostrar diferenças de abundância de organismos por esbarrarem na dificuldade de instalação das armadilhas de coleta, rotineiramente utilizadas. Contudo, para uma maior praticidade de implantação e de determinação do nível populacional de organismos edáficos, foi avaliada uma metodologia alternativa à armadilha de Tretzel (modificada), o método Provid, para a coleta da fauna edáfica, proposto pelos autores deste trabalho. Os dois métodos foram instalados em nove diferentes áreas, com três repetições por método. As áreas diferiram quanto à localização, tipo de solo e cobertura vegetal. Os parâmetros avaliados para a população da fauna edáfica foram riqueza: abundância e índice de diversidade de Simpson. Diferenças estatísticas significativas não foram encontradas para os dois métodos de coleta de organismos edáficos entre as nove áreas analisadas para os parâmetros avaliados. Portanto, pode-se concluir que a metodologia de coleta da fauna edáfica pelo método Provid pode ser utilizada de uma forma tão eficiente quanto à armadilha de Tretzel modificada. O método Provid é prático e fácil de usar.

Palarvas-chave: diversidade biológica; mesofauna; armadilha.

\section{ABSTRACT}

Study of soil organisms population may not detect differences of organisms number due to the difficulty of pitfall installation methods routinely used. However, to a better practice and determination of population level of soil organisms, it was evaluated an alternative methodology to the pitfall Tretzel (modified). The method is called Provid, for the collection of the soil organisms, proposed by the authors of this work. The two methods were installed in nine different areas, with three replication for each method. The areas differed in terms of location, soil type and vegetable covering. The appraised parameters were richeness, abundance and Simpson's index. As results, it was not found significant statistical differences for the two methods of collection of organism's edaphios among the nine analyzed areas, for the appraised parameters. Therefore, that the methodology of collection of the soil organisms for the Provid method can be used as efficient as the pitfall Tretzel modified method. The Provid method is practical and easy to be managed.

Keywords: biological diversity; mesofauna; pitfall tramp.

\section{INTRODUÇÃO}

Uma importante característica do solo é a vasta e complexa relação existente entre os seres que nele habitam, os quais o usam como abrigo e fonte de nutriente para seu desenvolvimento. O solo está entre um dos mais complexos habitats do globo, sendo o sistema biológico pobremente conhecido (Assad, 1997; Coleman e Grossley, 1995). Os processos de um ecossistema são influenciados por uma gama de fatores incluindo clima, vegetação, solo e fauna (Wright e Coleman, 2000). Ao interferir na dinâmica da decomposição dos resíduos orgânicos do solo, a fauna edáfica desempenha um importante papel na manutenção da cadeia alimentar e do fluxo energético.

O uso de diferentes coberturas vegetais e de práticas culturais podem atuar diretamente sobre a população da fauna edáfica. Esse efeito, muitas vezes, está relacionado à permanência de resíduos orgânicos sobre a superfície do solo. As coberturas geralmente formam uma camada espessa de folhas mortas, com vários estratos de matéria fresca e em decomposição, capaz de abrigar uma fauna mais diversificada (Canto,

1. Biológa, Dr ${ }^{\mathrm{a}}$., Professora Adjunta do Departamento de Solos, Centro de Ciências Rurais, Universidade Federal de Santa Maria, Campus Universitário, CEP 97105-900, Santa Maria (RS). zaida@ccr.ufsm.br

2. Mestrando pelo Programa de Pós-Graduação em Agronomia, Centro de Ciências Rurais, Universidade Federal de Santa Maria, Campus Universitário, CEP 97105-900, Santa Maria (RS).

3. Doutorando pelo Programa Pós-Graduação em Ciência do Solo, Centro de Ciências Rurais, Universidade Federal de Santa Maria, Campus Universitário, CEP 97105-900, Santa Maria (RS).

Recebido para publicação em 27/09/2005 e aceito em 16/10/2006. 
1996). Sistemas monoculturistas, ao fornecerem um único substrato alimentar, propiciam o desenvolvimento de determinados grupos faunísticos em detrimento de outros (Baretta et al., 2003; Assad, 1997).

Um dos maiores problemas encontrados ao amostrar a fauna edáfica deriva do fato dos organismos viverem nas mais diferentes camadas do perfil do solo, o que dificulta sua coleta. Os métodos de contagem populacional são, muitas vezes, destruidores da área em estudo, o que não é desejável quando se trabalha com áreas experimentais. Visando a avaliar metodologias de coleta, Primavesi e Primavesi (1968) montaram experimento comparativo entre o método de Tullgren - Berlese e as trampas de Tretzel. O primeiro método demonstrou não ser tão eficiente, pois durante a extração da amostra a agitação do solo pode fazer com que a fauna terrícola fuja para camadas mais profundas do solo e/ou para outros lugares, no caso dos representantes das camadas superficiais (Primavesi e Primavesi, 1968). Os resultados mostram que a população mais ativa como colêmbolos, formigas, aranhas, entre outros, foram capturados nas trampas de Tretzel e não na amostra de solo submetida ao extrator de Tullgren - Berlese, enquanto que a população menos ativa, pode ser coletada pelo segundo método, apesar de alguns organismos morrerem no solo antes de se deslocarem até o funil.

O uso de armadilhas de Tretzel apresenta alguns inconvenientes, como transporte de material e dificuldades na instalação. Isso torna difícil sua instalação em grande quantidade, sobretudo quando a área experimental se situa distante da instituição de pesquisa. Dessa forma, testou-se um método que fosse prático, econômico, de rápida instalação e que possuísse eficiência semelhante a dos métodos comumente utilizados.

\section{MATERIAL E MÉTODOS}

O presente trabalho foi realizado em Santa Maria e São Francisco de Assis, RS, durante o mês de setembro de 2000. Foram escolhidas glebas conforme descrito abaixo, buscando uma maior variabilidade entre os locais avaliados:

$\left.1^{\text {a }}\right)$ Numa propriedade particular, localizada no Distrito de Água Boa, município de Santa Maria e distante 11,5 km do Campus da UFSM. O solo é um Argissolo Vermelho Distrófico arênico (EMBRAPA, 1999). O declive médio é de 5\%, situado no terço médio de uma coxilha. A vegetação nos últimos 20 anos (1980-2000) é de campo nativo pobre, sendo os solos ácidos (pH 5,1), com baixa saturação de bases (41,5\%) e pobres em matéria orgânica $(0,6 \%)$. As áreas foram: (Área 1) Plantio direto com cobertura de inverno constituída por aveia preta (Avena strigosa Schreb.) + ervilha forrageira (Pisum sativum L. var. arvense (L.) Tzreler) sobre campo natural roçado e dessecado e (Área 2) campo natural roçado.

$2^{\mathrm{a}}$ ) Na área pertencente ao Departamento de Solos da Universidade Federal de Santa Maria (UFSM), Santa Maria, RS, Brasil. As áreas cujos efeitos foram testados foram coxilha em pousio (Área 3) e coxilha com $80 \mathrm{~m}^{3} \mathrm{ha}^{-1}$ de esterco líquido de suíno (Área 4). O solo é semelhante ao da área 1.

$3^{3}$ ) $\mathrm{Na}$ área também pertencente ao Departamento de Solos da UFSM, onde a área foi a várzea (Área 5). O solo é um Planossolo Hidromórfico Eutrófico arênico (EMBRAPA, 1999). O clima das glebas 1, 2 e 3 é do tipo "Cfa" pela classificação de Köeppen (Moreno, 1961).

$4^{\mathrm{a}}$ ) No município de São Francisco de Assis, RS, Brasil, também numa propriedade particular, onde as áreas foram eucaliptus de dois anos (Área 6), pinus (Área 7), eucaliptus com seis anos de implantação (Área 8) e campo nativo (Área 9). O solo dessa área é um Neossolo Quartzarênico típico (EMBRAPA, 1999), situado na região fisiográfica da Depressão Central, com precipitação pluviométrica média de $1511 \mathrm{~mm}$ anuais, não havendo nenhum mês com precipitação média inferior a $95 \mathrm{~mm}$. A evaporação média anual, é de $903 \mathrm{~mm}$ representando 60\% do volume precipitado (Souto, 1985). A temperatura mínima média e máxima média no mês de setembro de 2000 foi de 11,0 e $22,6^{\circ} \mathrm{C}$ respectivamente. Ocorreu uma pequena estiagem antes ( 9 dias) e depois (5 dias) da instalação das armadilhas à campo, sendo que dois dias antes e no dia da coleta ocorreram chuvas de 33,4 e $8,0 \mathrm{~mm}$ respectivamente.

Os indivíduos da macro e mesofauna foram coletados com Trampa de Tretzel (Tretzel, 1952) modificado, em que se usaram um suporte para vaso (prato número dois) fixado ao solo por meio de uma haste metálica no formato de "L" invertido para substituir a telha de barro e, metade de uma garrafa de plástico, pet (capacidade de dois litros) substituindo o vidro de $1000 \mathrm{~mL}$ (Figura 1). 


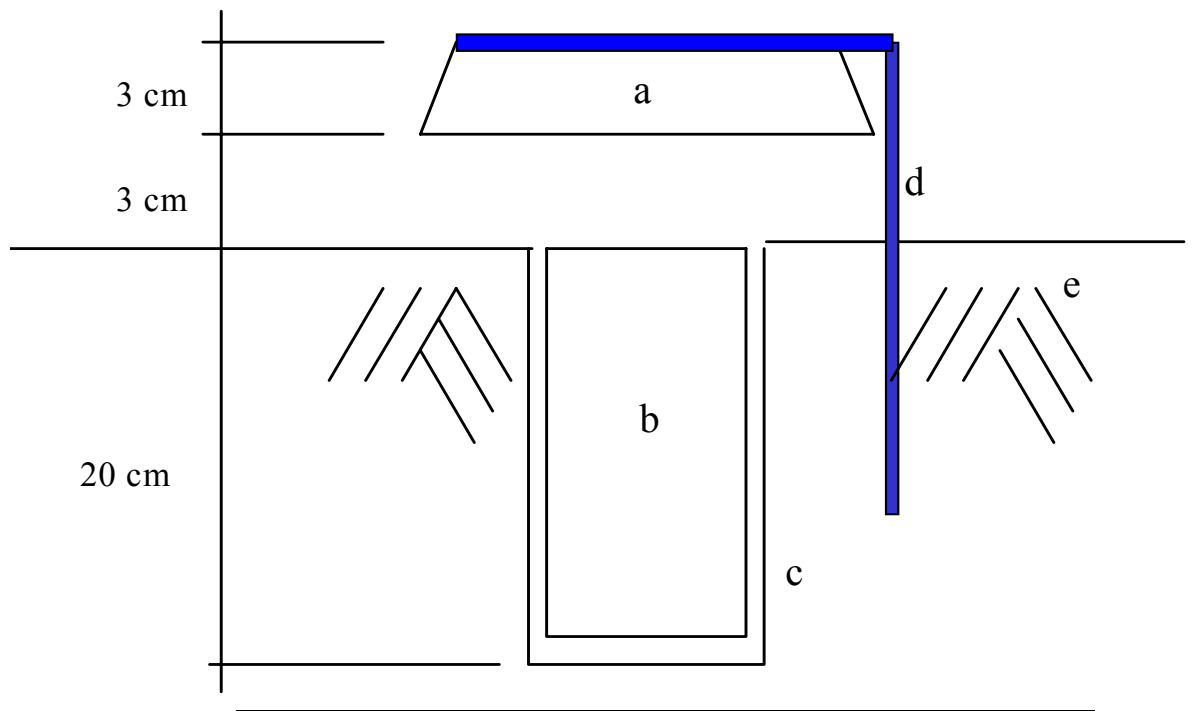

a) prato plástico de vaso de flor número 2

b) $1 / 2$ garrafa plástica (pet) de dois litros

c) trincheira

d) haste metálica $10 \times 20 \mathrm{~cm}$

e) solo

FIGURA 1: Método modificado da armadilha de Tretzel.

FIGURE 1: Tretzel modified method.

A outra trampa utilizada foi a Trampa Provid (Figura 2), idealizada pelos autores deste trabalho. Ela é constituída por uma garrafa de plático tipo Pet com capacidade de dois litros, contendo quatro aberturas na forma de janelas com dimensões de $6 \times 4 \mathrm{~cm}$ na altura de $20 \mathrm{~cm}$ de sua base. Cada armadilha foi instalada a campo por um período de sete dias, contendo em seu interior $200 \mathrm{~mL}$ de álcool $70 \%$ mais 3-5 gotas de formol a $2 \%$. Elas foram enterradas no solo de modo que os bordos dos frascos ficassem ao nível da superfície do solo. Foi realizada apenas uma época de coleta de cada método, com três repetições por área, totalizando 27 repetições por método. Após cada coleta, procederam-se a identificação e contagem dos organismos em laboratório.
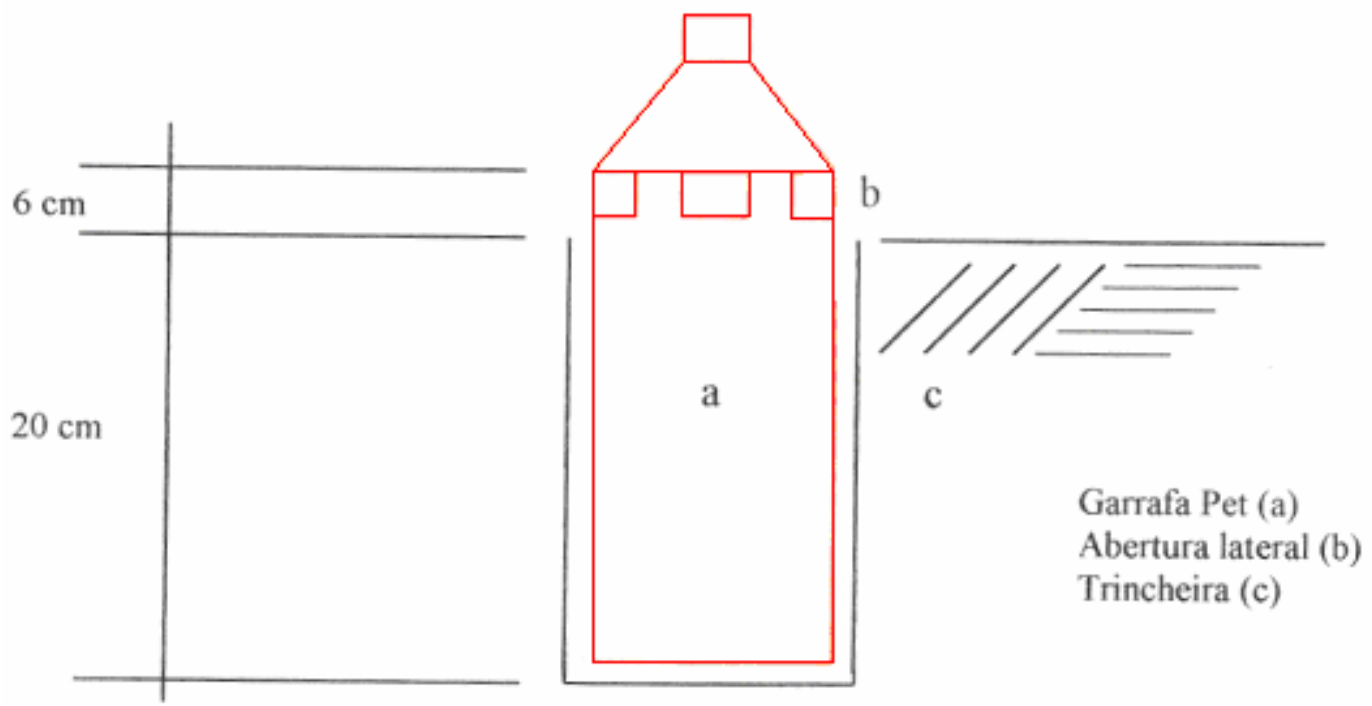

FIGURA 2: Método da armadilha Provid.

FIGURE 2: Provid pitfall method. 
Com base na contagem e identificação em nível de grupo dos organismos edáficos dos sistemas acima mencionados, foram determinados por meio dos parâmetros: riqueza, abundância e Índice de Diversidade de Simpson (Begon et al., 1990). Para identificação quanto à classe e ordem, utilizou-se uma lupa biocular com capacidade de aumento de $40 \mathrm{X}$. Para os colêmbolos da área coxilha com $80 \mathrm{~m}^{3} \mathrm{ha}^{-1} \mathrm{de}$ esterco de suíno, fizeram-se lâminas contendo dez indivíduos para observação ao microscópio aumento $100 \mathrm{X}$ para identificação au nivel de família (Coleman e Grossley , 1995).

Os dados de contagem obtidos foram submetidos à transformação $\sqrt{(X+0,5)}$, e os parâmetros determinados foram analisados segundo o modelo fatorial $2 \times 9$ (dois métodos de coleta e nove áreas) em delineamento inteiramente casualizado com três repetições para cada área pelo teste F. Posteriormente, para os efeitos significativos (método ou área) aplicou-se o teste de Tukey ao nível de significância de 5\%.

\section{RESULTADOS E DISCUSSÕES}

A interação da comunidade biótica com o solo tem um papel vital na produção e manutenção da qualidade do solo, por isso os organismos do solo representam um elemento-chave no desenvolvimento da agricultura sustentável (Aquino, 1999). Foram coletados 5.601 organismos do solo, sendo destes, 3.211 pelo método Provid e 2390 do método Tretzel modificado. Os organismos foram distribuídos em 19 grupos: Acarina, Aranae, Chilopoda, Coleoptera, Collembola, Crustacea, Diplopoda, Diptera, Hemiptera, Himenoptera, Isoptera, Lepdoptera, Molusca, Odonata, Oligochaeta, Orthoptera, Protura, Escorponidae, Tisanoptera e larvas. O grupo Protura não foi encontrado em nenhuma das áreas quando se utilizou o método Provid, mas foi encontrado na área de várzea com o método de Tretzel modificado (Tabela 1, 2 e Figura 3).

Os grupos predominantes foram Acarina, Collembola e Himenoptera em todos as áreas, correspondendo a 20,75\% (496 indivíduos), 47,49\% (1135 indivíduos) e 17,87\% (427 indivíduos), respectivamente, perfazendo juntos $86,11 \%$ do total de organismos coletados pelo método Tretzel modificado. Para o método Provid, dos indivíduos coletados, 10,74\% (345 indivíduos) pertenciam ao grupo acarina, 35,56\% (1142 indivíduos) ao grupo collembola e 42,4\% (1362 indivíduos) ao grupo Himenoptera, sendo esses três grupos equivalente a $88,72 \%$ do total de indivíduos coletados por esse método (Tabela $1 \mathrm{e}$ 2).

A maior abundância foi registrada na área 1, com 759 indivíduos, no método de coleta Provid (Figura 1). Considerando-se ainda o mesmo método de coleta, tem-se, na seqüência, a área campo nativo, com 707 indivíduos, a área de coxilha com esterco suíno, com 596 indivíduos e a área de coxilha, com 453 indivíduos. A menor abundância de organismos neste método de coleta foi encontrada na área de pinus, com 74 indivíduos coletados e área campo nativo 2, com 76 indivíduos. No método de coleta Tretzel modificado (Tabela 1, Figura 3), a maior abundância ocorreu na área de coxilha, com um total de 468 indivíduos coletados, ficando em valor próximo a área de várzea, que apresentou 452 indivíduos e a área coxilha com esterco suíno, com 417 indivíduos. O menor número de indivíduos foi observado na área campo nativo 2 (94 indivíduos), seguidos da área de eucalipto 2 anos, com 127 indivíduos e área de plantio direto aveia preta com 163 indivíduos (Tabela 1, Figura 3). Apesar da grande diferença numérica encontrada entre métodos de coleta e áreas, com relação à abundância de indivíduos, não ocorreu diferenças estatísticas significativas.

Os microartrópodos, ácaros e colêmbolos são os mais abundantes da mesofauna (Aquino, 1999 ; Coleman e Crossley, 1995), além de servirem como indicadores da condição biológica do solo, pela sua sensibilidade às alterações ambientais (Damé et al., 1996). Apesar da maior quantidade de indivíduos do grupo dos himenópteros nas áreas de plantio direto aveia preta e campo nativo, em geral os grupos dominantes foram ácaros e colêmbolos nos dois métodos de coleta (Tabela 1 e 2). A dominância de tais grupos da fauna edáfica também foi constatada por Luizão (1985), Oliveira e Franklin (1993), Damé et al. (1996) e Azevedo et al. (2000), analisando ambientes no qual houve ação antrópica. Um maior número de indivíduos desses grupos também foi detectada por Duarte (2000), trabalhando em fragmentos de Araucária com interferência pastoril. 
TABELA 1: Número médio de organismos coletados pelo método Provid, média de três repetições (A1: plantio direto aveia preta; A2: campo nativo; A3: coxilha; A4: coxilha com estreco suíno; A5: várzea; A6: eucalipto com 2 anos; A7: pinus; A8: eucalipto 6 anos; A9: campo nativo 2).

TABLE 1: Awerage number of soil fauna organisms collected by Provid method, three repetition awerage (A1: direct plantation- black oat; A2: native field 1; A3: rest coxilha; A4: coxilha with swine manure; A5: varzea; A6: 2-year-old eucalytpus; A7: pinus; A8: 6-year-old eucalytpus; A9: native field 2).

\begin{tabular}{l|c|c|c|c|c|c|c|c|c}
\hline \multirow{2}{*}{ Organismo } & \multicolumn{1}{c}{ Área } \\
\cline { 2 - 10 } & 1 & 2 & 3 & 4 & 5 & 6 & 7 & 8 & 9 \\
\hline Acarina & 43 & 19 & 158 & 58 & 24 & 8 & 2 & 27 & 6 \\
Aranae & 2 & 2 & 3 & 5 & 13 & 2 & 7 & 9 & 2 \\
Chilopoda & - & 1 & 1 & - & - & - & - & - & - \\
Coleoptera & 14 & 2 & 12 & 8 & 14 & 8 & 3 & 9 & 6 \\
Collembola & 36 & 19 & 237 & 478 & 161 & 75 & 18 & 103 & 15 \\
Crustacea & - & - & 2 & 1 & - & - & - & - & - \\
Diplopoda & - & - & - & - & 1 & - & - & - & - \\
Diptera & 21 & 21 & 7 & 11 & 36 & 5 & 3 & 8 & 7 \\
Hemiptera & 4 & 4 & 2 & - & 1 & 1 & 3 & 1 & 2 \\
Himenoptera & 614 & 623 & 19 & 13 & 7 & 3 & 33 & 17 & 33 \\
Isoptera & 21 & 11 & 8 & 17 & 3 & 2 & 1 & 3 & 1 \\
Lepidoptera & 1 & - & 1 & 1 & - & - & - & - & 1 \\
Molusca & 1 & 1 & 1 & - & - & - & - & 1 & - \\
Odonata & - & - & - & 1 & - & - & - & - & - \\
Oligochaeta & 1 & - & - & - & - & - & - & - & 1 \\
Orthoptera & 1 & 1 & 2 & 2 & 1 & 1 & 4 & 1 & 1 \\
Scorponidae & - & 1 & - & - & - & - & - & - & - \\
Tisanoptera & - & 1 & - & - & - & - & - & - & - \\
Larvas & - & 1 & - & 1 & - & 1 & - & - & 1 \\
\hline Total de grupos & 12 & 14 & 13 & 12 & 10 & 10 & 9 & 10 & 12 \\
Total de organismos & 759 & 707 & 453 & 596 & 261 & 106 & 74 & 179 & 76 \\
\hline
\end{tabular}

TABELA 2: Número médio de organismos da fauna coletado pelo método de Tretzel, média de três repetições (A1: plantio direto aveia preta; A2: campo nativo; A3: coxilha; A4: coxilha com estreco suíno; A5: várzea; A6: eucalipto com 2 anos; A7: pinus; A8: eucalipto 6 anos; A9: campo nativo 2).

TABLE 2: Awerage number of soil fauna organisms collected by modified Tretzel method, three repetition awerage (A1: direct plantation- black oat; A2: native field 1; A3: rest coxilha; A4: coxilha with swine manure; A5: varzea; A6: 2-year-old eucalytpus; A7: pinus; A8: 6-year-old eucalytpus; A9: native field 2).

\begin{tabular}{|c|c|c|c|c|c|c|c|c|c|}
\hline \multirow[t]{2}{*}{ Organismo } & \multicolumn{9}{|c|}{ Área } \\
\hline & 1 & 2 & 3 & 4 & 5 & 6 & 7 & 8 & 9 \\
\hline Acarina & 39 & 24 & 179 & 65 & 36 & 11 & 91 & 44 & 7 \\
\hline Aranae & 5 & 4 & 4 & 4 & 23 & 3 & 4 & 8 & 2 \\
\hline Chilopoda & - & - & 1 & - & - & - & - & 1 & - \\
\hline Coleoptera & 6 & 6 & 11 & 10 & 7 & 4 & 4 & 11 & 3 \\
\hline Collembola & 23 & 41 & 216 & 291 & 302 & 95 & 33 & 82 & 52 \\
\hline Crustacea & - & - & 1 & 1 & 1 & - & - & - & - \\
\hline Diplopoda & - & - & - & - & - & 4 & - & - & - \\
\hline Diptera & 6 & $1-$ & 9 & 11 & 66 & 2 & 5 & 4 & 5 \\
\hline Hemiptera & 2 & 4 & 1 & 1 & 2 & 1 & 2 & 1 & 1 \\
\hline Himenoptera & 77 & 222 & 31 & 24 & 6 & 2 & 28 & 19 & 18 \\
\hline Isoptera & 4 & 3 & 11 & 9 & 4 & 4 & 1 & 1 & 1 \\
\hline
\end{tabular}


TABELA 2: Continuação ...

TABLE 2: Continued ...

\begin{tabular}{l|c|c|c|c|c|c|c|c|c}
\hline \multirow{2}{*}{ Organismo } & \multicolumn{9}{c}{ Área } \\
\cline { 2 - 10 } & 1 & 2 & 3 & 4 & 5 & 6 & 7 & 8 & 9 \\
\hline Lepidoptera & - & - & 1 & - & - & - & - & 1 & - \\
Molusca & - & 1 & - & - & 1 & - & - & - & - \\
Odonata & - & - & - & - & 1 & - & - & - & - \\
Oligochaeta & - & - & - & - & - & - & - & 1 & 1 \\
Orthoptera & 1 & - & 1 & - & 2 & 1 & 9 & - & 1 \\
Protura & - & - & 1 & - & - & - & - & - & - \\
Scorponidae & - & 2 & - & - & - & - & - & 1 & 1 \\
Tisanoptera & - & - & - & - & 1 & - & - & - & 1 \\
Larvas & - & - & 1 & 1 & - & - & - & 1 & 1 \\
\hline Total de grupos & 9 & 10 & 14 & 10 & 13 & 10 & 9 & 13 & 13 \\
Total de organismos & 163 & 317 & 468 & 417 & 452 & 127 & 177 & 175 & 94 \\
\hline
\end{tabular}

No método Provid (Tabela 1, Figura 3), as áreas que apresentaram uma maior riqueza foram a área de campo nativo, com 14 grupos coletados, a área de coxilha, com 13 grupos, seguidos pela área plantio direto aveia preta, coxilha com esterco suino e campo nativo, todos com 12 grupos de organismos coletados. Para esse método, a área de pinus apresentou a menor riqueza, com a presença de nove grupos nas amostras coletadas. A riqueza de organismos, nesse caso, refere-se ao número de grupos presentes nas amostras coletadas em cada área, para ambos os métodos. No método Tretzel modificado (Tabela 2, Figura 3), a maior riqueza foi observada na área de coxilha, com 14 grupos de organismos coletados, seguido pelas áreas várzea, eucalipto 6 anos e campo nativo 2, todos com 13 grupos de organismos, sendo que, para esse método, as áreas de plantio direto-aveia e pinus apresentaram a menor riqueza, composta por apenas nove grupos de organismos.

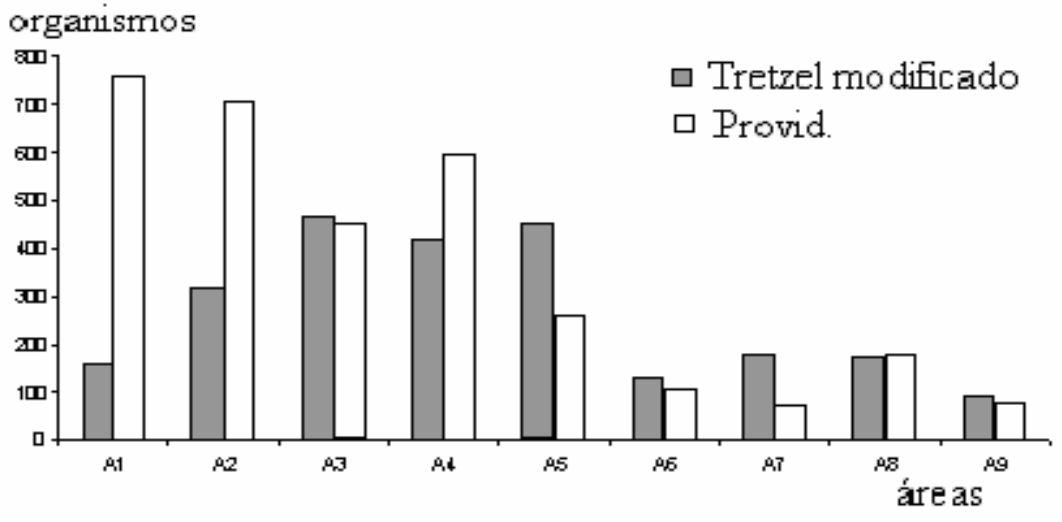

FIGURA 3: Adundância da fauna edáfica por dois métodos de coleta. A1: plantio direto aveia preta; A2: campo nativo; A3: coxilha; A4: coxilha com estreco suíno; A5: várzea; A6: eucaliptus com 2 anos; A7: pinus; A8: eucaliptus 6 anos; A9: campo nativo 2

FIGURE 3: Abundance of soil fauna by two colletion methods. A1: direct plantation- black oat; A2: native field 1; A3: rest coxilha; A4: coxilha with swine manure; A5: varzea; A6: 2-year-old eucalytpus; A7: pinus; A8: 6-year-old eucalytpus; A9: native field 2.

Não houve diferença estatística significativa na análise da riqueza de organismos tanto para as áreas quanto métodos de coletas de organismos avaliados.

Os resultados obtidos não apresentaram diferença significativa com relação ao efeito das áreas, dentro dos métodos de coleta. Entretanto, quando os métodos foram avaliados em separado, houve diferença significativa entre áreas para determinados grupos avaliados (Tabela 3).

Os dois métodos de coleta apresentaram diferença estatística entre as áreas (locais de coleta) em relação aos grupos coletados. Neste sentido, para o método Provid (Tabela 3), a área de pinus, apresentou 
maior número de orthoptera, sendo as áreas de várzea e campo nativo 2, as que apresentaram a menor população. Para ácaros, as áreas de coxilha pousio, coxilha esterno de suíno e plantio direto aveia-preta foram significativamente melhores que as demais áreas. Os ácaros são considerados os mais numerosos artrópodos do solo, o que reflete na diversidade de habitat alimentar do grupo.

A população de ácaros em ambos os métodos de coleta, apresentou as mesmas áreas com maior população, constatando-se que a adição de $80 \mathrm{~m}^{3} /$ ha de esterco suíno, parece exercer influência sobre a população de ácaros, foi observado, tanto para o método Provid, quanto para o método Tretzel modificado (Tabela 3, Figura 4).

Para colêmbolos, destaca-se a área de coxilha com esterco diferindo significativamente das demais. O grupo himenóptera, não diferiu estatisticamente em nenhuma área. Para isoptera, a área com maior população foi a área plantio direto sobre campo nativo, enquanto que a área com pinus foi a que apresentou a menor população desses organismos. Para o grupo díptera, a área de várzea foi a que apresentou maior população, diferindo das demais, sendo a área de pinus a com menor população (Tabela 3).

Os colêmbolos também são amplamente distribuídos e abundantes no solo e na serrapilheira. $\mathrm{O}$ principal efeito da atividade do colêmbolos é a promoção do processo de decomposição no solo. Isso ocorre pela alimentação direta da vegetação em decomposição e hifas de fungos, e indiretamente pelo estímulo dos microorganismos envolvidos na decomposição (Aquino, 1999). A população de colêmbolos é grandemente influenciável pela presença de material orgânico (Luizão,1985), sendo considerado como oportunistas por crescerem rapidamente sob condições adequadas (Coleman e Grossley, 1995). Isso ficou evidenciado pela área coxilha com pousio, que apresentou a maior população, sendo significativamente superior às demais áreas (Tabela 3, Figura 5).

TABELA 3: Médias de organismos coletados em cada tratamento pelos método de coleta de Tretzel modificado e Provid.

TABLE 3: Awerage number of organisms collected by modified collected Tretzel and Provid method.

\begin{tabular}{|c|c|c|c|c|c|c|c|c|c|}
\hline \multirow[t]{2}{*}{ Área } & \multicolumn{9}{|c|}{ Tretzel Modificado } \\
\hline & Aca & Ara & Cole & Col & Dip & Hem & Hym & Iso & Ort \\
\hline Plantio direto aveia preta & $39 \mathrm{Bc}$ & $5 \mathrm{~b}$ & $6 \mathrm{a}$ & $23 \mathrm{~B}$ & $6 \mathrm{~b}$ & $2 \mathrm{a}$ & $77 \mathrm{ab}$ & $4 \mathrm{a}$ & $1 \mathrm{~b}$ \\
\hline Campo nativo 1 & $24 \mathrm{Bc}$ & $4 \mathrm{~b}$ & $6 \mathrm{a}$ & $41 \mathrm{~B}$ & $10 \mathrm{~b}$ & $4 \mathrm{a}$ & $222 \mathrm{ab}$ & $3 \mathrm{a}$ & $0 \mathrm{~b}$ \\
\hline Coxilha pousio & $179 \mathrm{~A}$ & $4 \mathrm{~b}$ & $11 \mathrm{a}$ & $216 \mathrm{Ab}$ & $9 \mathrm{~b}$ & $1 \mathrm{a}$ & $31 \mathrm{~b}$ & $11 \mathrm{a}$ & $1 \mathrm{ab}$ \\
\hline Coxilha esterco suíno & $65 \mathrm{Abc}$ & $4 \mathrm{~b}$ & $10 \mathrm{a}$ & $291 \mathrm{~A}$ & $11 \mathrm{~b}$ & $1 \mathrm{a}$ & $24 \mathrm{~b}$ & $9 \mathrm{a}$ & $0 \mathrm{~b}$ \\
\hline Várzea & $36 \mathrm{Bc}$ & $23 \mathrm{a}$ & $7 \mathrm{a}$ & $302 \mathrm{~A}$ & $66 \mathrm{a}$ & $2 \mathrm{a}$ & $6 \mathrm{~b}$ & $4 \mathrm{a}$ & $2 a b$ \\
\hline Eucaliptus 2 anos & $11 \mathrm{Bc}$ & $3 \mathrm{~b}$ & $4 \mathrm{a}$ & $95 \mathrm{Ab}$ & $2 b$ & $1 \mathrm{a}$ & $2 b$ & $4 \mathrm{a}$ & $1 \mathrm{~b}$ \\
\hline Pinus & $91 \mathrm{Ab}$ & $4 \mathrm{~b}$ & $4 \mathrm{a}$ & $33 \mathrm{~B}$ & $5 \mathrm{~b}$ & $2 \mathrm{a}$ & $28 \mathrm{~b}$ & $1 \mathrm{a}$ & $9 \mathrm{a}$ \\
\hline Eucaliptus 6 anos & $44 \mathrm{Bc}$ & $8 a b$ & $11 \mathrm{a}$ & $82 \mathrm{Ab}$ & $4 \mathrm{~b}$ & $1 \mathrm{a}$ & $19 \mathrm{~b}$ & $1 \mathrm{a}$ & $0 \mathrm{~b}$ \\
\hline Campo & $7 \mathrm{C}$ & $2 b$ & $3 \mathrm{a}$ & $52 \mathrm{~B}$ & $5 \mathrm{~b}$ & $1 \mathrm{a}$ & $18 \mathrm{~b}$ & $1 \mathrm{a}$ & $1 \mathrm{ab}$ \\
\hline \multirow[t]{2}{*}{ Área } & \multicolumn{9}{|c|}{ Provid } \\
\hline & Aca & Ara & Cole & Col & Dip & Hem & Hym & Iso & Ort \\
\hline$\overline{\text { Planti }}$ & $43 \mathrm{Ab}$ & $2 \mathrm{a}$ & $14 \mathrm{a}$ & $36 \mathrm{c}$ & $21 \mathrm{ab}$ & $4 \mathrm{a}$ & $614 \mathrm{~A}$ & $21 \mathrm{~A}$ & $1 \mathrm{ab}$ \\
\hline $\mathrm{Cam}$ & $19 \mathrm{~B}$ & $2 \mathrm{a}$ & $2 \mathrm{a}$ & $19 \mathrm{c}$ & $21 \mathrm{ab}$ & $4 \mathrm{a}$ & $623 \mathrm{~A}$ & $11 \mathrm{Abc}$ & $1 \mathrm{ab}$ \\
\hline Coxil & $158 \mathrm{~A}$ & $3 \mathrm{a}$ & $12 \mathrm{a}$ & $237 \mathrm{~b}$ & $7 \mathrm{ab}$ & $2 \mathrm{a}$ & $19 \mathrm{~A}$ & $8 \mathrm{Abc}$ & $2 a b$ \\
\hline Coxilha & $58 \mathrm{Ab}$ & $5 \mathrm{a}$ & $8 \mathrm{a}$ & $478 \mathrm{a}$ & $11 \mathrm{ab}$ & $0 \mathrm{a}$ & $13 \mathrm{~A}$ & $17 \mathrm{Ab}$ & $2 a b$ \\
\hline Várz & $24 \mathrm{~B}$ & $13 \mathrm{a}$ & $14 \mathrm{a}$ & $161 \mathrm{~b}$ & $36 \mathrm{a}$ & $1 \mathrm{a}$ & $7 \mathrm{~A}$ & $3 \mathrm{Abc}$ & $1 \mathrm{~b}$ \\
\hline Eucaliptus 2 anos & $8 \mathrm{~B}$ & $2 \mathrm{a}$ & $8 \mathrm{a}$ & $75 \mathrm{c}$ & $5 \mathrm{~b}$ & $1 \mathrm{a}$ & $3 \mathrm{~A}$ & $2 \mathrm{Bc}$ & $1 \mathrm{ab}$ \\
\hline Pinus & $2 \mathrm{~B}$ & $7 \mathrm{a}$ & $3 \mathrm{a}$ & $18 \mathrm{c}$ & $3 \mathrm{~b}$ & $3 \mathrm{a}$ & $33 \mathrm{~A}$ & $1 \mathrm{C}$ & $4 \mathrm{a}$ \\
\hline Eucali & $27 \mathrm{~B}$ & $9 \mathrm{a}$ & $9 \mathrm{a}$ & $103 \mathrm{bc}$ & $8 \mathrm{ab}$ & $1 \mathrm{a}$ & $17 \mathrm{~A}$ & $3 \mathrm{Bc}$ & $1 \mathrm{ab}$ \\
\hline Campo nativo 2 & $6 \mathrm{~B}$ & $2 \mathrm{a}$ & $6 \mathrm{a}$ & $15 \mathrm{c}$ & $7 \mathrm{ab}$ & $2 \mathrm{a}$ & $33 \mathrm{~A}$ & $1 \mathrm{Bc}$ & $1 \mathrm{~b}$ \\
\hline
\end{tabular}

Em que: $\mathrm{Aca}=$ Acarina; $\mathrm{Ara}=$ Aranida; Cole $=$ Coleoptero; $\mathrm{Col}=$ Collembola; Dip = Diptera; Hem = Hemiptera; Hym

$=$ Hymenoptera; Isso = Isoptera; Ort = Orthoptera. Médias não-seguidas por mesma letra diferem pelo teste de Tukey a $5 \%$ de significância. 


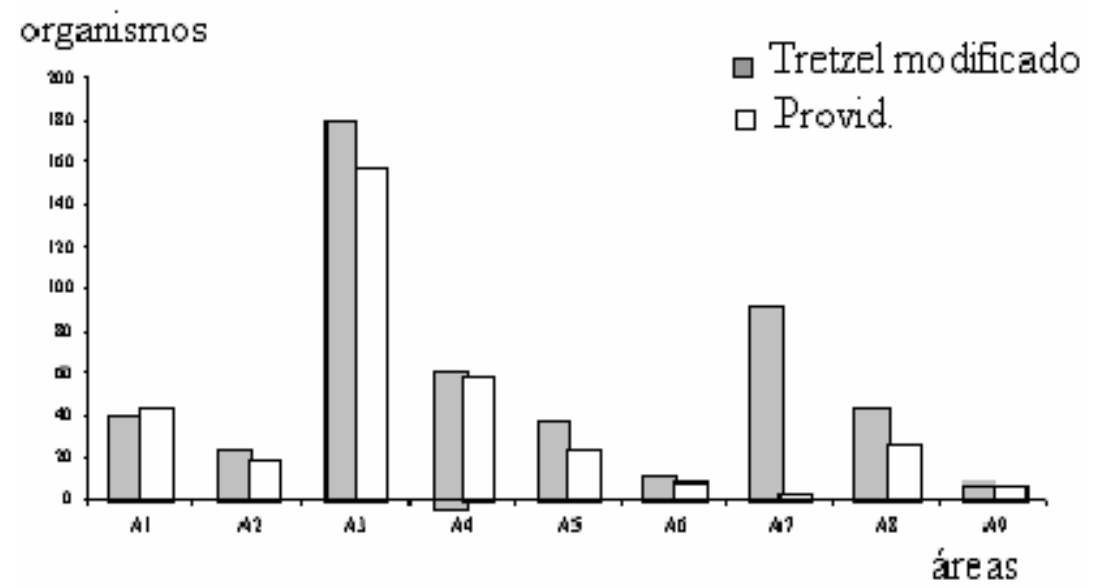

FIGURA 4: Número de ácaros coletados por dois métodos, em: A1: plantio direto aveia-preta; A2: campo nativo; A3: coxilha; A4: coxilha com estreco suíno; A5: várzea; A6: eucaliptus com 2 anos; A7: pinus; A8: eucaliptus 6 anos; A9: campo nativo 2

FIGURE 4: Number of acarina collected by the two methods, in A1: direct plantation- black oat; A2: native field 1; A3: rest coxilha; A4: coxilha with swine manure; A5: várzea; A6: 2-year-old eucalytpus; A7: pinus; A8: 6-year-old eucalytpus; A9: native field 2.

A identificação dos indivíduos coletados nessa área, em nível de família (Coleman e Grossley, 1995), demonstrou a predominância de indivíduos pertencentes a família Entomobrydae (99\%) e poucos exemplares pertencentes à família Sminthuridae (1\%). Nota-se que ambos os métodos apresentaram o mesmo resultado nas coletas, demonstrando a eficiência do método Provid para coleta da fauna edáfica.

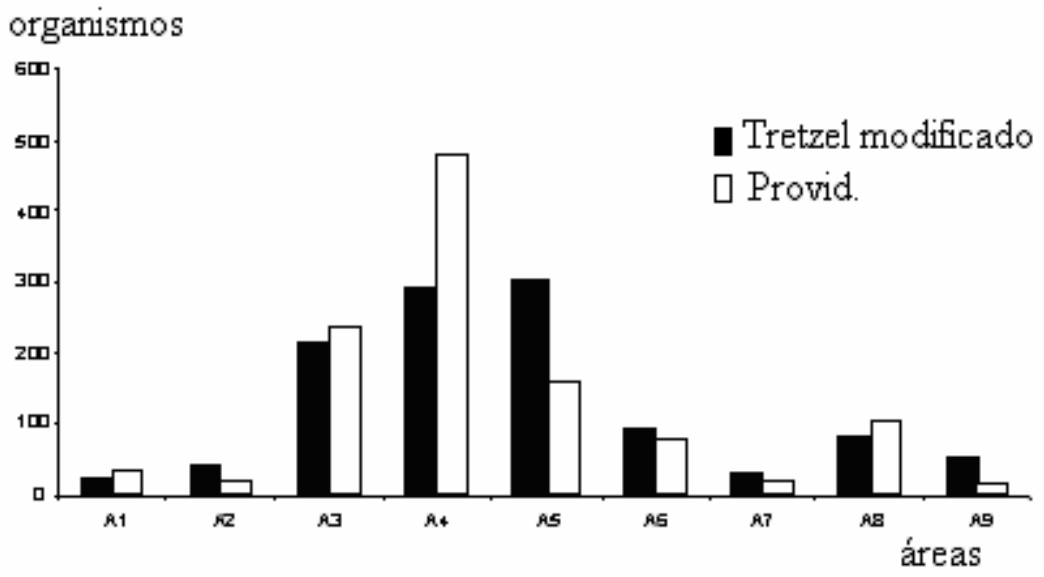

FIGURA 5: Número de colêmbolos coletados por dois métodos em: A1: plantio direto aveia-preta; A2: campo nativo; A3: coxilha; A4: coxilha com estreco suíno; A5: várzea; A6: eucaliptus com 2 anos; A7: pinus; A8: eucaliptus 6 anos; A9: campo nativo 2

FIGURE 5: Number of colembolos collected by the two methods, in A1: direct plantation-black oat; A2: native field 1; A3: rest coxilha; A4: coxilha with swine manure; A5: varzea; A6: 2-year-old eucalytpus; A7: pinus; A8: 6-year-old eucalytpus; A9: native field 2.

No método Tretzel modificado (Tabela 4), coletaram-se mais ácaros nas áreas coxilha, coxilha com esterco suíno e pinus, e menos na área de campo nativo 2. Para colêmbolos, a maior população foi coletada nas áreas de coxilha com esterco suino e várzea, diferindo das demais áreas, sendo a menor população, verificada na área de plantio direto aveia-preta. A maior população de orthoptera foi coletada na área de pinus e a menor na área de campo nativo. Para díptero a área de várzea apresentou a maior população desse organismo, enquanto a área eucaliptus dois anos apresentou a menor população. Nesse método, o grupo himenóptera diferiu significativamente, apresentando maior população na área de campo nativo e menor na área de eucalipto com 2 anos. 
O grupo himenóptero apresentou diferença significativa apenas no método Tretzel modificado, sendo observado que as áreas de plantio direto-aveia e campo nativo diferiram significativamente das demais áreas (Figura 5), sendo atribuídas provavelmente ao fato das armadilhas terem sido instaladas próximas a locais de maior trânsito de formigas, resultando numa maior variabilidade dos resultados.

Silva e Carvalho (2000), trabalhando com sistemas de plantio direto, encontraram uma dominância do grupo de coleópteros. Um maior número desses indivíduos, especialmente os coprófagos, seria esperado na área com adição de esterco, o que não se confirmou, já que as médias das áreas (para os dois métodos) não apresentaram diferenças, contrastando com os dados obtidos por Duarte (2000), em que, na presença de dejetos bovinos, esse grupo teve um aumento considerável. A inexpressiva quantidade de coleópteros na área 4 deve-se provavelmente ao tempo transcorrido após a aplicação do dejeto suíno (4 a 5 meses), ou por este ter sido manejado na forma líquida, possuindo um teor de matéria seca inferior a $3 \%$.

O índice de diversidade de Simpson avalia toda uma população amostrada, levando em consideração a abundância de organismos e riqueza destes, presentes na comunidade, em síntese, quanto maior esse índice, maior será a diversidade da comunidade avaliada (Begon et al., 1990). Assim, nas áreas avaliadas (Tabela 4), a maior diversidade foi observada na área campo nativo 2, com um índice de diversidade de Simpson de 4,5 seguido da área de pinus, com um índice de 3,5, ambos no método de coleta Provid. No mesmo método, a menor diversidade foi encontrada na área de coxilha com esterco suíno, com índice de 1,5 e área 2, com índice igual a 1,74, que diferiram estatisticamente da área campo nativo 2. As demais áreas não diferiram entre si. Analisando os dados referentes ao método TretzeL modificado, o maior índice de diversidade $(3,4)$, foi observado na área de eucalipto com 6 anos, seguido pela área de plantio direto aveia-preta, com índice de diversidade de 3,31. Os menores índices foram encontrados na área 6 , sendo este igual a 1,72 e área de pinus, com índice de diversidade de 1,97. Não houve diferença significativa na análise do índice de diversidade de Simpson no método Tretzel modificado para as áreas avaliadas.

TABELA 4: Riqueza, abundância e índice de Simpson da fauna edáfica em cada área pelos métodos Provid e Tretzel modificado.

TABLE 4: Richness, abundance and Simpon's index of soil organisms in each area by the Tretzel modified and Provid method.

\begin{tabular}{l|r|rr|r|r|r}
\hline \multirow{2}{*}{ Área } & \multicolumn{3}{|c|}{ Provid } & \multicolumn{3}{c}{ Tretzel } \\
\cline { 2 - 7 } & \multicolumn{1}{|c}{ Riqueza } & Abundância & Índice Simpson & Riqueza & Abundância & Índice Simpson \\
\hline Plantio direto aveia-preta & $9,3 \mathrm{a}$ & $757,00 \mathrm{a}$ & $3,12 \mathrm{ab}$ & $7,6 \mathrm{a}$ & $162,66 \mathrm{a}$ & $3,31 \mathrm{a}$ \\
Campo nativo & $10,0 \mathrm{a}$ & $705,33 \mathrm{a}$ & $1,73 \mathrm{~b}$ & $9,3 \mathrm{a}$ & $318,33 \mathrm{a}$ & $2,04 \mathrm{a}$ \\
Coxilha pousio & $10,0 \mathrm{a}$ & $450,00 \mathrm{a}$ & $2,35 \mathrm{ab}$ & $10,0 \mathrm{a}$ & $465,33 \mathrm{a}$ & $2,69 \mathrm{a}$ \\
Coxilha esterco suíno & $9,6 \mathrm{a}$ & $590,00 \mathrm{a}$ & $1,48 \mathrm{~b}$ & $8,0 \mathrm{a}$ & $414,47 \mathrm{a}$ & $1,97 \mathrm{a}$ \\
Várzea & $7,3 \mathrm{a}$ & $259,67 \mathrm{a}$ & $2,46 \mathrm{ab}$ & $9,3 \mathrm{a}$ & $450,00 \mathrm{a}$ & $2,09 \mathrm{a}$ \\
Eucaliptus 2 anos & $7,6 \mathrm{a}$ & $104,00 \mathrm{a}$ & $1,95 \mathrm{ab}$ & $8,0 \mathrm{a}$ & $125,33 \mathrm{a}$ & $1,71 \mathrm{a}$ \\
Pinus & $7,6 \mathrm{a}$ & $74,00 \mathrm{a}$ & $3,50 \mathrm{ab}$ & $7,0 \mathrm{a}$ & $176,00 \mathrm{a}$ & $2,87 \mathrm{a}$ \\
Eucaliptus 6 anos & $8,0 \mathrm{a}$ & $176,00 \mathrm{a}$ & $2,57 \mathrm{ab}$ & $8,3 \mathrm{a}$ & $171,00 \mathrm{a}$ & $3,39 \mathrm{a}$ \\
Campo nativo 2 & $8,3 \mathrm{a}$ & $74,00 \mathrm{a}$ & $4,49 \mathrm{a}$ & $6,6 \mathrm{a}$ & $91,00 \mathrm{a}$ & $1,75 \mathrm{a}$ \\
\hline CV\% & 18,04 & 120,34 & 35,86 & 29,00 & 50,45 & 27,16 \\
\hline
\end{tabular}

Em que: Médias não-seguidas por mesma letra diferem pelo teste de Tukey a $5 \%$ de significância.

As alterações na densidade e na diversidade da fauna são observadas em ecossistemas que sofreram algum tipo de intervenção na sua cobertura vegetal (Azevedo et al, 2000), pois a diversidade estrutural de uma comunidade de plantas correlaciona-se com a diversidade de animais que habitam aquela comunidade (Correia, 2002). Tem sido dado pouca atenção para o papel que a agrosilvicultura deve ter na proteção da biodiversidade. Teoricamente, os sistemas agroflorestais deveriam ser melhores do que as monoculturas para a conservação da diversidade biológica porque os sistemas agroflorestais são estruturalmente mais diversos (Correia, 2002). O baixo número de indivíduos encontrados nas áreas de pinus e eucaliptus pode ser atribuído entre outros fatores ao fato desses sistemas representarem também sistemas monoculturistas de exploração vegetal.

Tendo em vista que os dados submetidos à análise estatística não apresentarem diferença significativa entre os métodos de coleta, tanto para abundância e riqueza, quanto para o índice de diversidade 
de Simpson (Tabela 4), concluímos que o método Provid possui confiabilidade para ser utilizado a campo para coleta dos organismos da fauna edáfica.

\section{CONCLUSÃO}

O método Provid de coleta dos organismos do solo pode ser usado com a mesma eficiência que o método da armadilha de Tretzel modificado, sendo também mais prático e fácil de manejar.

\section{AGRADECIMENTOS}

Ao Dr. David Colleman, pelos seus valiosos conselhos e sugestões. Ao suporte financeiro do Departamento de Solos, Centro de Ciências Rurais, UFSM e ao Programa de Pós-Graduação em Agronomia.

\section{REFERÊNCIAS BIBLIOGRÁFICAS}

AQUINO, A.M. Meso e macrofauna do solo e sustentabilidade agrícola: perspectivas e desafios para o século XXI. In: CONGRESSO BRASILEIRO DE CIÊNCIA DO SOLO, 27., Brasília, 1999. Anais... Brasília: Sociedade Brasileira de Ciência do Solo, 1999. 1 CD-ROM.

ASSAD, M.L.L. Fauna do Solo. In; VARGAS, M. A .T.; HUNGRIA, M. (Ed.). Biologia dos solos dos cerrados. Planaltina: EMBRAPA-CPAC, 1997. p.363-443.

AZEVEDO, V. F., LIMA, D. A., CORREIA, M. E. F., AQUINO, A. M., SANTOS, H. P. Fauna de solo em diferentes sistemas de plantio e manejo no planalto médio do Rio Grande do Sul. In: REUNIÃO BRASILEIRA DE FERTILIDADE DO SOLO E NUTRIÇÃO DE PLANTAS, 24., Santa Maria, 2000 ; REUNIÃO BRASILEIRA SOBRE MICORRIZAS, 7., Santa Maria, 2000 ; SIMPÓSIO BRASILEIRO DE MICROBIOLOGIA DO SOLO, 6. Santa Maria, 2000 ; REUNIÃO BRASILEIRA DE BIOLOGIA DO SOLO, FERTIBIO, 3. Santa Maria, 2000. Anais.... Santa Maria: Sociedade Brasileira de Ciência do Solo : Sociedade Brasileira de Microbiologia, 2000. 1 CDROM.

BEGON, M., HARPER, J. L., TOWNSEND, C.T. Ecology, individuals, population and communities. 2.ed. Oxford: Blackwell Scientific Publications, 1990. 945p.

BARETTA, D.; SANTOS, J.C.P.; MAFRA, A .L.; WIKDNER, L.P.; MIQUELLUTI, D.J. Fauna edáfica avaliada por armadilhas de catação manual efetada pelo manejo do solo na região oeste catarinense. Revista Ciência Agroveterinárias, v.2, p.97-106, 2003.

CANTO, A.C. Alterações da mesofauna do solo causadas pelo uso de cobertura com plantas leguminosas na Amazônia Central. Revista Ciências Agrárias, v.4, n.5, p.79-94, 1996.

COLEMAN, D. C., GROSSLEY, D. A. Fundamentals of soil ecology. San Diego: Academic Press, 1995. 205p.

CORREIA, M. E. F. Relações entre a diversidade da fauna de solo e o processo de decomposição e seus reflexos sobre a estabilidade dos ecossistemas. Seropédica: Embrapa Agroecologia. 18p. (Documento 156).

DAMÉ, P.R.V.; QUADROS, F.L.F.; KERSTING, C.E.B.; TRINDADE, J.P.P.; ANTONIOLLI, Z.I. Efeitos da queimada seguida de pastoreio ou diferimento sobre o resíduo, temperatura do solo e mesofauna de uma pastagem natural. Ciência Rural, Santa Maria, v.26, p.391-396, 1996.

DUARTE, M. M. Abundância de microartrópodes do solo em gradientes de mato, borda e campo na Fazenda Boa Vista, Muitos Capões, RS. In: REUNIÃO BRASILEIRA DE FERTILIDADE DO SOLO E NUTRIÇÃO DE PLANTAS, 24., Santa Maria, 2000 ; REUNIÃO BRASILEIRA SOBRE MICORRIZAS, 7., Santa Maria, 2000 ; SIMPÓSIO BRASILEIRO DE MICROBIOLOGIA DO SOLO, 6., Santa Maria, 2000 ; REUNIÃO BRASILEIRA DE BIOLOGIA DO SOLO, FERTIBIO, 3. Santa Maria, 2000. Anais.... Santa Maria: Sociedade Brasileira de Ciência do Solo : Sociedade Brasileira de Microbiologia, 2000. 1 CD-ROM.

EMPRESA BRASILEIRA DE PESQUISA AGROPECUÁRIA. Sistema Brasileiro de Classificação de Solos. Rio de Janeiro: Embrapa Solos, 1999.

LUIZÃO, F. J. Influência da calagem e adubação orgânica na mesofauna e nas propriedades físicas de um LATOSSOLO AMARELO textura argilosa. Revista Brasileira de Ciência do Solo, v.9, p.81-84, 1985.

MORENO, J. A. Clima do Rio Grande do Sul. Porto Alegre: Secretaria da Agricultura, 1961.

OLIVEIRA, E.P.; FRANKLIN, E. Efeito do fogo sobre a mesofauna do solo: recomendações em áreas queimadas. Pesquisa Agropecuária Brasileira, Brasília, n.28, p.357-369, 1993.

PRIMAVESI, A.M.; PRIMAVESI, A. Diferenças entre resultados da trampa e do aparelho Berlese. In: CONGRESSO LATINO AMERICANO DE BIOLOGIA DO SOLO: Progressos em Biodinâmica e Produtividade do Solo, 2.,1968, 
Santa Maria. Anais... Santa Maria, 1968. p.145-148.

SILVA, R. A., CARVALHO, G. S. Ocorrência de insetos na cultura do milho em sistema de plantio direto, coletados com armadilhas-de-solo. Ciência Rural, v. 30, p.199-203, 2000.

SOUTO, J.J.P. Desertos, uma ameaça? : estudos dos núcleos de desertificação na fronteira sudoeste do RS. Porto Alegre: Secretaria da Agricultura, 1985.

TRETZEL, E. Technik und bedeutung des fallenfanges für oekologische untersuchungen. Zoology Anz., Jena, n.155, p. 276-287, 1952.

WRIGHT, C. J. ; COLEMAN, D. C. Cross-site comparison of soil microbial biomass, soil nutrient status, and nematode trophic groups. Pedobiologia, n.44, p.2-23, 2000. 